\title{
Contribution and legacy of John Wing, 1923-2010
}

\author{
Traolach S. Brugha, ${ }^{*}$ Lorna Wing, * John Cooper* and Norman Sartorius*
}

\section{Summary}

The death of Professor John Wing, one of the giants of 20thcentury British and world psychiatry, rightly deserves to be marked by a tribute in the British Journal of Psychiatry. This article has been prepared by four people who knew John personally and through his work, his partner in private and work life, a colleague in Great Britain and one abroad and a pupil, which are set out as four separate contributions. John was born on 22 October 1923. He died on 18 April 2010, aged 87

\section{Declaration of interest}

None.

\section{John Wing's work at the Institute and the College}

\section{By Terry Brugha}

Observations and recollections received from many colleagues and friends around the world have played a part in my tribute to John Wing. John was Director of the MRC Social Psychiatry Unit at the Institute of Psychiatry, London, for 25 years. Under John's direction the MRC Unit developed and tested ideas about social causation and their contribution to the maintenance of severe mental illness. His unit provided a unique training route for at least 11 subsequent professors in Great Britain: Julian Leff, Paul Bebbington, Chris Brewin, Til Wykes, Elizabeth Kuipers, Michael Power, David Fowler, Graham Thornicroft, Dinesh Bhugra, Martin Orrell and myself. Many other psychiatrists and psychologists were influenced by his ideas. He provided a lighttouch intellectual environment that supported innovation and creativity. Upon his retirement in 1989, the Royal College of Psychiatrists appointed him as the first Director of the College's Research Unit. Under his leadership, the Unit assembled a team of people who developed methodologies for the assessment of activities, such as audit, quality control and the assessment of need for services in a population. One of the many products of this unit was the very short and simple Health of the Nation Outcome Scale (HoNOS), ${ }^{1}$ since translated into at least six different languages and extensively used in routine care in Great Britain and Australia.

Karl Popper's philosophy of science influenced John's epidemiological and clinical studies. It also shaped his views of the nature of classification in psychological medicine. He regarded the medical method as a process of developing syndromes and then using these as the basis for testing theories about causes, mechanisms and treatments. In this view, syndromes and their determinants were theoretical constructs, which had value as long as they were corroborated. However, they might be jettisoned if they were refuted and a better theory was available. Long before the arrival of the DSM-III ${ }^{2}$ and ICD $-10^{3}$ diagnostic criteria he successfully demonstrated the importance of the basic principles of assessment and diagnosis and the need for care and attention to the definition of mental disorders. His establishment of operationalised classifications of psychiatric disorder based on precise psychopathological descriptions was thus an example of his overall scientific approach to psychiatry. Based on these ideas he became best known for the development of the Present State Examination (PSE) ${ }^{4}$ to systematically assess and categorise disordered mental states, together with the computer algorithm, CATEGO, a precursor of operationalised diagnostic criteria. In

*These authors contributed equally to this work. its current form as the Schedules for Clinical Assessment in Neuropsychiatry (SCAN), ${ }^{5}$ it continues to be learnt and used by psychiatric students and researchers throughout the world. His influence outside Great Britain was considerable therefore. For example, he was hugely influential in India, and also in a number of European countries including in particular Denmark and The Netherlands, where his ideas continue to influence training at the highest levels.

One former colleague described John as distrustful of 'explain-it-all' grand theories and instead he put great effort into developing a 'common language' for describing psychopathology, establishing this as a fundamental science of psychiatry, whereas previously it might have been regarded only as an area of philosophical concern. John was described well in the following words by Assen Jablensky: 'He was a man of a rich inner life which he only sparingly disclosed, except in his acerbic wit and the precision of his arguments in collegial discussion'.

John was greatly liked by all his staff in the MRC Social Psychiatry Unit at the Maudsley and Institute of Psychiatry. He was always easy to approach. He seemed most at ease enjoying a good supper with a glass or two of wine with fellow researchers. I recall in particular two occasions: our first evening at the World

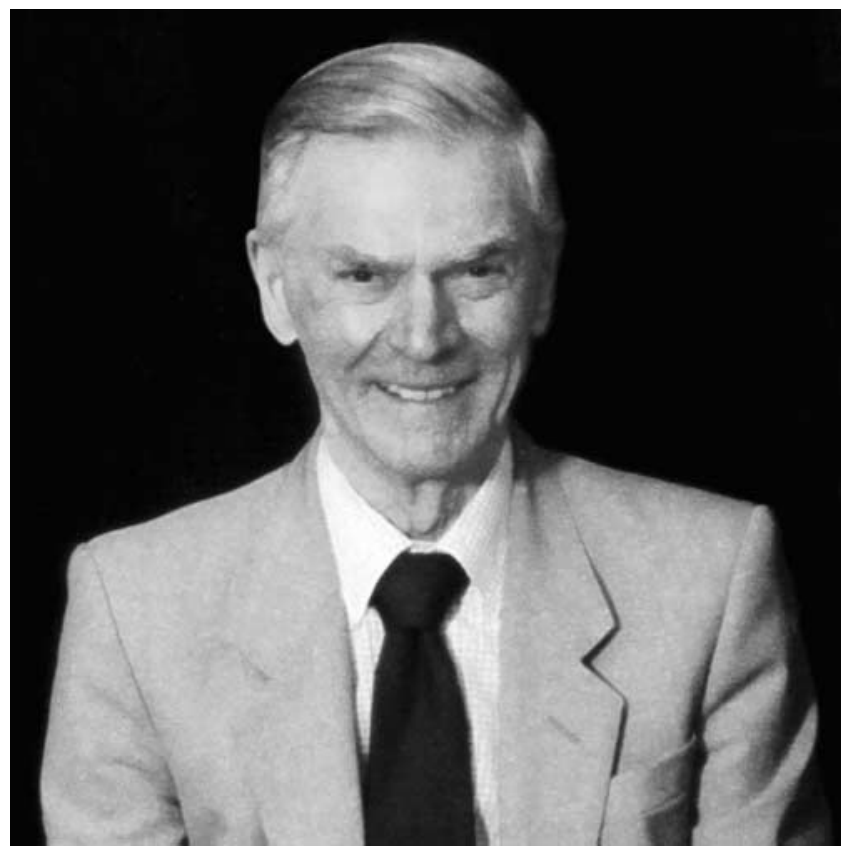

John Wing, 1923-2010 
Health Organization (WHO) in Geneva at a superb French steak restaurant; and a wonderful dinner to honour his work with WHO on the SCAN, at the Royal College in the early 1990s when the College Research Unit was getting underway.

Personally I found John to be a very warm and welcoming person. We first met in 1979 in Dublin when he gave a lecture at the Royal College of Surgeons in Ireland, following which I approached him to introduce myself. John encouraged me to get in touch when I arrived at the Maudsley in 1980. Being invited then to work with John in his Unit was for me a dream come true in 1982, and there followed five of the best years I can recall in my career. On joining the unit as a rooky researcher he offered some excellent advice on building good relationships with experienced non-clinical post-doctoral researchers. I particularly recall from his supervision of my MD thesis the generous and patient time given to encouraging and helping me to produce a logically argued thesis abstract. He was also greatly encouraging as my career developed after 1987 at the University of Leicester. Throughout the world there are many who owe John a similar debt of gratitude.

\section{John Wing's life}

\section{By Lorna Wing}

John was born in 1923, the second of three children. His father was the manager of a bookshop. He had been gassed when he was a solider during the First World War and died of pneumonia when John was nearly 5 years old. John's mother died of a heart attack a few months later. John and his older sister Barbara were placed in a boarding school for orphans whereas their younger sister lived with an aunt and uncle. John and Barbara spent school holidays with various aunts and uncles.

John did well at school and won a scholarship to a grammar school when he was 13 years old. By this time he had decided he wanted to follow a career in medicine. He was aware of the financial problems since none of his aunts and uncles could have afforded university fees. He was 16 when the Second World War started in 1939. Discussing his future with his uncle, John learnt that, after the First World War, the government paid university fees for ex-service men. He made the decision to join the forces in the hope that he would be supported in medical school when the war ended - assuming of course that we won the war. In 1941 John joined the Navy and became a navigator in the fleet air arm. John spent most of the war based in Australia, involved in bombing raids on enemy shipping. He returned to the UK at the end of the war and, as he had hoped and dreamed, he received a government grant to attend University College London medical school and then University College Hospital.

Starting in 1948 John studied for the first MB at University College London. I did this part of the course at my school and then went to University College London for the second MB course in 1949, which is where John and I met. At the beginning of this course, the students gathered in the anatomy department dissecting room to be assigned bodies for dissection. By pure chance, John and I were assigned, with four other students, to body number 13, which is how we met.

We married in 1951 while studying clinical medicine at University College Hospital. We were both interested in psychiatry and both went into this field. In 1956 our daughter Susan (Susie) was born. She was a much wanted child, but within a few weeks we were worried about her because her sucking was very poor and she hardly slept at night, screaming most of the time. Later we observed her lack of communication and social interaction, lack of pretend play and her repetitive behaviour. We had no idea what was wrong with her because we had learnt nothing about autism in our medical or psychiatric studies.
When Susie was about 3 years old, John went to a lecture given by Mildred Creak and light dawned. It was obvious that Susie had classic Kanner's autism. She also had moderate to severe intellectual disabilities. Having a child with autism has led to the break-up of some marriages. However, Susie drew us even closer together. She was also the reason for my work in the field of childhood developmental disorders. In her own way, Susie was very attached to both of us and we were very attached to her. John had always wanted more children, but we were too aware of the high chance of having another child with autism. When Susie died in 2009 we were both devastated by losing her.

Colleagues are writing about John's research work. I will just add one small anecdote. During the 1960s John and I were both invited to Russia, me to see services for adults with intellectual disabilities and John to see adults with psychiatric disorders. I was quite impressed with the services for people with moderate intellectual disabilities that I was allowed to visit. John, however, as an expert in the field of schizophrenia, was asked to see two or three people in a long-stay hospital who were political dissidents. For political reasons, those in charge wanted John to confirm that these individuals had schizophrenia. John saw them, found absolutely no evidence of any mental illness and refused to confirm the official diagnosis. The authorities had chosen the wrong man if they wanted someone to agree with them in the absence of any evidence. John was not that sort of person.

In his last long illness, in which he lost all his memories and skills, John still recognised me and was pleased to see me. He had always loved music (he had learnt to play the guitar) and up to the end he enjoyed listening to classical music, which was a pleasure to me as well. He died in April this year (2010). I shall always miss him and hold on to fond memories of him.

\section{John Wing and the development of the PSE and SCAN}

\section{By John Cooper}

John Wing's contributions to social psychiatry are characterised by an unusual breadth of outlook, manifest in a multidisciplinary approach. His collaboration with George Brown in their study of three mental hospitals was a good example of this. His interest in the welfare and assessment of patients with long-standing and disabling mental illness led to him joining Aubrey Lewis's Social Psychiatry Unit at the Institute of Psychiatry in London. He later became the Director of this Unit for many productive years.

One of the rating scales he produced was the origin of the PSE, which has progressed under his guardianship to a tenth edition. This now forms the heart of SCAN. The PSE has had a fundamental influence upon many types of psychiatric research, following its adoption by the World Health Organization in 1965 for use in the International Pilot study of Schizophrenia (IPSS). Its use in this multinational study resulted in its further development into the ninth edition; this has now been translated into more than twenty languages, and can be used in many different cultures. One of the strengths of the PSE/SCAN system is that it does not force its users into following any particular diagnostic system. It is simply a comprehensive catalogue of the experience of the patient, expressed in terms of symptoms. The user can turn these symptoms into diagnoses according to whatever diagnostic system is required.

Aubrey Lewis liked to establish links between the Institute of Psychiatry and other prominent sections of the University of London, and it was through one of these links that I first encountered John Wing. I was starting a period of work in 1962 under James Douglas on the National Survey of Child Health and Development at the London School of Economics, but was 
also given a desk in the Social Psychiatry unit. Although the desk was seldom used, the link itself proved to be invaluable when John Wing organised the psychiatric members of the Social Psychiatry Unit to do a trial of the sixth edition of the PSE on out-patients. This was the first large-scale use of the PSE, and its success showed that the interview was ready to face the world.

The PSE has retained its essential form of being a comprehensive catalogue of symptoms, and it is now accompanied by a set of computer programs that produce diagnoses from both the ICD and the DSM systems if required. John once remarked to me that during the development of the earliest versions of the PSE, his wife Lorna had a significant input into some of the sections covering symptoms such as worry and muscular tension.

John Wing was also an important player in the negotiations that were going on around that time concerned with the establishment of the UK end of the US/UK diagnostic project at the Institute of Psychiatry. Together with Michael Shepherd, he was very helpful to me, as I was at that time an innocent at large in the world of international negotiations. He was also one of the most important advisers to Tsung-yi Lin and Norman Sartorius about the design and progress of the IPSS. For both of these pioneering studies, the PSE was exactly the sort of rating instrument that was required.

Another of John Wing's interests was the use of psychiatric case registers. Aubrey Lewis was always doubtful about the feasibility and usefulness of case registers, but John had the confidence to persist and set up the Camberwell Psychiatric Case Register, also with considerable input from Lorna. He was later the key person in the bringing together of the eight principal psychiatric case registers then in existence in the UK. The registers managed to harmonise their definitions and tabulations (a surprisingly difficult but very informative task) to produce a set of comparative tables.

John kept his professional and private lives separate, but nevertheless would always admit to enjoying a game of tennis. I have a fond memory of playing with him under floodlights at 3000 feet in Cali, Columbia at a meeting of the IPSS investigators in 1968. His favourite shot was an odd-looking top-spin forehand cross-court drive that was very effective, and certainly impressed our hosts.

His death marks the end of an era in which the development of psychiatry outside mental hospitals (that is, social and community psychiatry, and psychiatry in primary care), set in motion by Aubrey Lewis, was turned into a practical reality in the UK by the likes of John Wing and Michael Shepherd. Psychiatrists in many other countries regard the British contribution to this now international movement as specially important, and the work of John Wing was a major part of this.

\section{John Wing and international psychiatry}

\section{By Norman Sartorius}

I met John Wing during my stay at the Institute of Psychiatry in the mid-1960s but got to know him better when I joined the World Health Organization. At that time John Wing was closely involved in the planning of the International Pilot Study of Schizophrenia (IPSS). The IPSS was a bold undertaking, the first major international study of schizophrenia in nine countries differing in their cultures, health systems, traditions and medical ideology. John was one of the group - with Lyman Wynne, who was heading intramural psychiatry at the National Institute of Mental Health of the USA, and Professor Erik Stromgren who headed the Institute of Psychiatry in Aarhus, Denmark on whom Tsung-yi Lin, then the medical officer in charge of epidemiological and social psychiatry relied in the development of the study. Each of these four advisers had - in addition to their professional qualifications and position in the world of psychiatry - unique qualities that made Tsung-yi Lin invite them. For me each of the four was a source of information and wisdom invaluable in the work I had to do.

John excelled by the clarity of his contributions and his determination to get things done fast and well. In the years that followed we worked together in studies of schizophrenia, and in a variety of projects dealing with psychiatric epidemiology, and both of these qualities were immensely helpful. Leaders of psychiatric teams from the countries involved in the IPSS and in the Study of Determinants of Outcome of Severe Mental Disorders that followed the IPSS shared my opinion about John's qualities. His relationships with all of them were harmonious and friendly although he never hesitated or failed to say exactly what he felt, not always very diplomatically. I believe that they recognised his sincerity and his comments as an expression of his devotion to science and studies of schizophrenia.

I also had the pleasure of working with John, or watching him work, on projects that had no direct relationship with the programme of the World Health Organization. He was a key member of the Section of Epidemiology of the World Psychiatric Association and with it organised meetings on issues of central importance for public health. One of these, held in Aberdeen in 1969, remains particularly clear in my memory. John organised it with a small committee consisting of E. Gruenberg, E. H. Hare, G. Innes and K. Rawnsley and I had to present the first findings of the tests of reliability of the PSE that John and his colleagues had developed and that became the main assessment instrument of the IPSS. The list of participants contained names of many of the great figures of epidemiology and I was afraid that my presentation would not reach the high levels that the audience by its excellence deserved. John found time to encourage me before I gave my paper and praised me after I presented it. I felt very grateful for that: in a way I felt he helped me to gain admission to the court of the elite in psychiatric epidemiology.

As the years went by there were other occasions to meet and work together, often in international meetings and projects, as for example on his contribution to the drafting of the ICD-10 diagnostic guidelines and criteria for psychotic disorders. His contributions to these were consistently useful and highly respected and I believe that they added to his image as one of the great pioneers and makers of social and epidemiological psychiatry.

Traolach S. Brugha, MD, FRCPsych, Department of Health Sciences, University of Leicester, UK; Lorna Wing, MD, FRCPsych, National Autistic Society Centre for Social and Communication Disorders, Bromley, UK; John Cooper, FRCP, FRCPsych, DPM(Lond), University of Nottingham, UK; Norman Sartorius, MD, PhD, FRCPsych, Association for the Improvement of Mental Health Programmes, Geneva, Switzerland

Correspondence: Traolach S. Brugha, Department of Health Sciences, New Academic Unit, Leicester General Hospital, Gwendolen Road, Leicester LE5 4PW, UK. Email: tsb@le.ac.uk

First received 4 Oct 2010, final revision 8 Dec 2010, accepted 15 Dec 2010

\section{References}

1 Wing JK, Beevor AS, Curtis RH, Park SB, Hadden S, Burns A. Health of the Nation Outcome Scales (HoNOS): research and development. Br J Psychiatry 1998; 172: 11-8.

2 American Psychiatric Association. Diagnostic and Statistical Manual of Mental Disorder (3rd edn) (DSM-IIII). APA, 1980.

3 World Health Organization. The ICD-10 Classification of Mental and Behavioural Disorders: Clinical Descriptions and Diagnostic Guidelines. WHO, 1992.

4 Wing JK, Cooper JE, Sartorius N. The Measurement and Classification of Psychiatric Symptoms. Cambridge University Press, 1974.

5 Wing JK, Babor T, Brugha T, Burke J, Cooper JE, Giel R, et al. SCAN. Schedules for Clinical Assessment in Neuropsychiatry. Arch Gen Psychiatry 1990; 47: 589-93. 